\title{
Seckel Syndrome
}

National Cancer Institute

\section{Source}

National Cancer Institute. Seckel Syndrome. NCI Thesaurus. Code C125488.

A rare autosomal recessive inherited syndrome caused by mutations in the ATR gene, RBBP8 gene, CENPJ gene, CEP152 gene, CEP63 gene, NIN gene, DNA2 gene, or TRAIP gene. It is characterized by intrauterine growth retardation, dwarfism, microcephaly, mental retardation, and a "bird-headed" facial appearance. 